\title{
Fibroblast Growth Factor 23 (FGF23) Levels, Phosphate Intake and its Association with Indices of Renal Handling of Phosphate in Healthy Volunteers
}

\author{
Noreen Abbas, Aysha Habib Khan*, Farooq Ghani and Imran Siddiqui \\ Aga Khan University Hospital, Stadium Road, P.O. Box 3500 Karachi 74800, Pakistan
}

\begin{abstract}
FGF23 is a novel phosphaturic hormone; we aimed to assess the FGF23 levels and its association with dietary phosphate intake and indices of renal handling of phosphate in this study. Prospective study was conducted in which dietary phosphate intake was assessed by food frequency questionnaire (FFQ) along with blood and spot urine samples were collected after overnight fast for determining serum phosphate, FGF23, fractional excretion of phosphate $\left(\mathrm{FePO}_{4}\right)$ and tubular maximum for phosphate (TmP/GFR). FGF23 (C-Term) was measured by a sandwich ELISA.

The mean dietary phosphate intake of eighty healthy adults (mean age of $29 \pm 5$ years) was $1220 \pm 426 \mathrm{mg}$; median FGF23 was $49.9 \mathrm{RU} / \mathrm{ml}(\mathrm{IQR}=33,76)$ and mean $\mathrm{FePO}_{4}$ was $7 \pm 4.7$. Subjects were stratified into two groups according to serum phosphate levels. Significant difference was not found in dietary phosphate intake and FGF23 levels in the two groups. However, TmP/GFR and creatinine were significantly different in the two groups. $\mathrm{FePO}_{4}$ was high in both the groups.

Overall a rising pattern of FGF23 levels was seen with increasing serum phosphate levels. Significant positive correlation was found between FGF23 and dietary phosphate $(r=0.22, p<0.05)$ and negative correlation was seen between FGF23 and $\mathrm{FePO}_{4}(r=-0.260, p<0.05)$.
\end{abstract}

Keywords: Phosphate; FGF23; TmP/GFR; 1, 25(OH $)_{2}$ Vitamin D; $\mathrm{FePO}_{4}$

\section{Introduction}

Fibroblast 23 (FGF23) is primarily expressed in osteocytes and in endothelial cells lining the venous sinusoids of bone marrow and thymus [1]. Most of its functions occur in the kidney through an FGF receptor (FGFR)/Klotho complex; and it acts opposite to vitamin D by inhibiting 1 alpha hydroxylase and stimulating 24 hydroxylase enzymes in the renal tubule. As a result, $1,25 \mathrm{OH}$ vitamin $\mathrm{D}$ catabolism is increased with decrease in production due to excess of FGF23 [2]. Moreover, the expression of type II sodium-dependent phosphate cotransporters (mainly NPT2a and NPT2c) is inhibited by FGF23 in cells of renal proximal tubules which reduces phosphate reabsorption and consequently increases urinary phosphate excretion.

FGF 23 also interacts negatively with PTH mRNA in contrast to CKD, where increased FGF23 is associated with secondary hyperparathyroidism. Due to these opposing verdicts; local and systemic confounding factors have been projected to modify FGF23 levels and taken together, it is advocated that PTH and FGF23 axis is similar to vitamin D-FGF23 loop [2].

Another main stimulus for FGF23 released is increased phosphate intake as evinced by the literature, as FGF23 levels were not increased by the rise in serum phosphate levels due to non-dietary interventions [3]. Literature showed that consumption of diet low in calcium and high in phosphorus have detrimental effects on the normal physiology of peak bone mass which leads to osteoporosis in later life. Both short term and longer consumption of phosphate causes increase in PTH levels and thus increases bone turnover. On the other hand despite minor rise in PTH levels, calcitriol showed a significant reduction or no change in concentrations.

As FGF23 is a novel regulator of phosphate homeostasis and its has actions on PTH and 1,25 $(\mathrm{OH})_{2}$ D metabolism and is considered key factor in bone cellular, metabolic, and mineralization functions. Hence, both over and under expression of FGF23 results in negatively affecting bone mineralization; while its deficiency leading to severe hypophosphatemia, hyper vitaminosis $\mathrm{D}$, and increased circulating calcium [2]. The extra renal functions of FGF23 are important apart from renal failure, as the association of FGF23 with adversative outcomes including cardiovascular changes is sturdier.

Studies showed that higher FGF23 levels are now associated with cardiovascular complications and death. Association of FGF23 concentrations with adversarial outcomes is stronger in patients with $\mathrm{CKD}$ as it is not captured by measurement of routine biomarkers for CKD i.e., eGFR or albuminuria [3].

FGF23 has not been studied in our population. We presumed that FGF23 is high in our subjects due to high dietary phosphate intake [4]. This has implications for the bone health and diagnosis and treatment of phosphate-wasting disorders and vitamin $\mathrm{D}$ metabolic defects. The purpose of this study was to explore FGF23 levels in healthy subjects and assess its relationship with serum phosphate; TmP/GFR, $\mathrm{FePO}_{4}$ and dietary phosphate.

*Corresponding author: Aysha Habib Khan, Aga Khan University Hospital, Stadium Road, P.O. Box 3500 Karachi 74800, Pakistan, Tel: 922134930051 E-mail: aysha.habib@aku.edu

Received October 31, 2015; Accepted Janaury 09, 2016; Published January 20 2016

Citation: Abbas N, Khan AH, Ghani F, Siddiqui I (2016) Fibroblast Growth Factor 23 (FGF23) Levels, Phosphate Intake and its Association with Indices of Renal Handling of Phosphate in Healthy Volunteers. J Nanomed Nanotechnol 7: 348. doi:10.4172/2157-7439.1000348

Copyright: (C) 2016 Abbas N, et al. This is an open-access article distributed under the terms of the Creative Commons Attribution License, which permits unrestricted use, distribution, and reproduction in any medium, provided the original author and source are credited. 
Citation: Abbas N, Khan AH, Ghani F, Siddiqui I (2016) Fibroblast Growth Factor 23 (FGF23) Levels, Phosphate Intake and its Association with Indices of Renal Handling of Phosphate in Healthy Volunteers. J Nanomed Nanotechnol 7: 348. doi:10.4172/2157-7439.1000348

Page 2 of 4

\section{Materials and Methods}

A prospective cross sectional study took place at Section of Clinical Chemistry, Department of Pathology and Laboratory Medicine, Aga Khan University, Karachi. The study was reviewed and accepted by the Ethical Review Committee, Aga Khan University Hospital.

Healthy subjects of either gender staff were recruited after informed consent. A performa including the demographics age, gender, ethnicity, occupation was filled at the time of drawing blood.

Blood sample was taken from study subjects after an overnight fast, in ethylene diamine tetra acetic acid (EDTA) and gel tubes for analysis of FGF23 and serum phosphate and creatinine respectively. At the same time subjects were asked to provide a spot urine sample for phosphate and creatinine measurements. Plasma was collected after centrifugation at $3000 \mathrm{rpm}$ for $5 \mathrm{~min}$. Aliquotting of plasma samples was performed, and tubes were labeled and kept at $-70^{\circ} \mathrm{C}$ till analysis of plasma FGF23, serum creatinine and phosphate.

Dietary information was recorded on food frequency questionnaires (FFQ) through a face-to-face interview with the principal investigator, and the duration of each interview took about 20 to 25 minutes. The FFQ was previously validated [5]. The raw composition of phosphate content in each food item was taken from the U.S. Department of Agriculture, Agricultural Research Service, and Nutrient data laboratory. In certain cases where this information was not available from the USDA, other local food composition tables were consulted [6]. Dietary data for phosphate content were totaled by multiplying the intake frequency of each food item by the phosphate content of the given portion sizes.

FGF23 levels (C-term) were measured by a sandwich enzyme linked immunosorbent assay (ELISA) from Immunotopics Inc. (San Clemente, California). Both normal and abnormal control materials were run to assure quality of analysis. The normal reference range for plasma FGF23 was taken as median $52.4 \mathrm{RU} / \mathrm{ml}[4,7,8]$.

Plasma and urinary phosphate and creatinine levels were measured by Synchron CX9 by Beckmann instruments Brea, California USA based on spectrophotometric principle. To ensure quality, two levels of controls (normal and abnormal) were run with each batch of plasma, serum and urinary phosphate and creatinine analysis. The laboratory participated in external proficiency testing from BIORAD laboratories California, USA for phosphate and creatinine every three months.

Values for serum phosphate, serum creatinine, urinary phosphate and creatinine were utilized for derivation of $\mathrm{FePO}_{4}$ and TmP/GFR by using these formulae [9]:

$$
\begin{aligned}
& \mathrm{TmP} / \mathrm{GFR}=\mathrm{S}_{\mathrm{PO} 4}-\left(\mathrm{U}_{\mathrm{PO} 4} \times \mathrm{S}_{\mathrm{cr}} / \mathrm{U}_{\mathrm{cr}}\right) \\
& \mathrm{FePO}_{4}=\left(\mathrm{U}_{\mathrm{PO} 4} \times \mathrm{S}_{\mathrm{cr}}\right) /\left(\mathrm{S}_{\mathrm{PO} 4} \times \mathrm{U}_{\mathrm{cr}}\right) \times 100 \%
\end{aligned}
$$

Normal range for TmP/GFR was $2.4-4.8 \mathrm{mg} / \mathrm{dl}$ and cutoff for normal $\mathrm{FePO}_{4}$ was taken as $<5 \%$.

SPSS version 19 was used to compute and analyze the data. Frequencies of gender were generated. Means and standard deviations for continuous variables (age, serum FGF23, serum and urinary phosphate and serum and urinary creatinine) and proportion for categorical variables (gender, ethnic origin, and education) was also computed. A confidence interval of $95 \%$, for the FGF23 was reported. Data of FGF23 was skewed so median value was reported along with interquartile ranges. We had also compared two groups of serum phosphate using Mann-Whitney U Test and association between log transformed FGF23, serum phosphate, dietary phosphate, serum creatinine, $\mathrm{FePO}_{4}$ and TmP/GFR using spearman's correlation coefficient.

Effect modifiers were controlled through age, gender, serum phosphate; dietary phosphate, $\mathrm{FePO}_{4}$, serum creatinine and $\mathrm{TmP} /$ GFR to see the impact on the outcome variable. A p-value of $<0.05$ was considered as significant and $\mathrm{p}$ value $<0.01$ as highly significant in all statistical analysis.

\section{Results}

Eighty subjects were recruited in the study. The mean age of the study subjects was $29 \pm 4.7$ years with $51 \%(n=41)$ being females. Table 1 shows the anthropometric details and biochemical parameters assessed in study subjects.

\section{Relation of serum phosphate with FGF23 and indices of renal handling}

Only one subject had high serum $\mathrm{P}(>4.5 \mathrm{mg} / \mathrm{dl})$, with high dietary phosphate intake $(1685.6 \mathrm{mg})$ and high $\mathrm{FePO}_{4}(8.5 \%)$ and FGF23 levels of $54.9 \mathrm{RU} / \mathrm{ml}$. This subject was excluded from final analysis.

Table 2 shows indices of renal handling, dietary phosphate intake and FGF23 levels in 79 subjects with low and normal serum phosphate levels. Six subjects (11\%) were identified to have low mean serum phosphate levels $(2.3 \pm 0.2 \mathrm{mg} / \mathrm{dl})$, the cause of which is not known. Mean TmP/GFR was low and $\mathrm{FEPO}_{4}$ was high in subjects with hypophosphatemia. FGF23 concentrations were increased in only 2 subjects, while the rest have levels less than the cut off.

Creatinine and TmP/GFR were significantly different between subjects with low and normal serum phosphate levels.

\section{Distribution of FGF23 and association with indices of renal handling}

Log FGF23 showed a statistically significant negative correlation with serum creatinine $(\mathrm{p}<0.05)$ and $\mathrm{FEPO}_{4}(\mathrm{p}<0.05)$. Significant association was not found with serum $\mathrm{PO}_{4}$, dietary phosphate and TmP/GFR (Table 3). However, with increase in median FGF23 quartiles, a downward trend is seen in serum phosphate and TmP/GFR and upward trend in $\mathrm{FePO}_{4}$ (Tables 4 and 5).

\begin{tabular}{|l|c|}
\hline $\begin{array}{l}\text { Gender } \\
\text { Male }\end{array}$ & $\begin{array}{l}49 \%(\mathrm{n}=39) \\
51 \%(\mathrm{n}=41)\end{array}$ \\
\hline $\begin{array}{l}\text { Female } \\
\text { (Yrs. })\end{array}$ & $29 \pm 4.7$ \\
\hline $\begin{array}{l}\text { Mean BMI } \\
\left(\mathrm{kg} / \mathrm{m}^{2}\right)\end{array}$ & $22.98 \pm 3.91$ \\
\hline $\begin{array}{l}\text { Mean Serum } \mathrm{PO}_{4} \\
(\mathrm{mg} / \mathrm{dl})\end{array}$ & $3.35 \pm 3.91$ \\
\hline $\begin{array}{l}\text { Mean TmP/GFR } \\
\text { (mg/dl) }\end{array}$ & $3.04 \pm 0.57$ \\
\hline $\begin{array}{l}\text { Mean FePO } \\
(\%)\end{array}$ & $7.0 \pm 4.7$ \\
\hline $\begin{array}{l}\text { Mean Dietary } \\
\text { Phosphate } \\
\text { (mg) }\end{array}$ & $1220 \pm 426$ \\
\hline $\begin{array}{l}\text { Median FGF-23 } \\
\text { (RU/ml) }\end{array}$ & $49.9(33-76.1)$ \\
\hline
\end{tabular}

Abbreviations used: BMI, Body Mass Index; FGF-23, Fibroblast growth factor 23 TmP/GFR, Tubular maximum re-absorption of phosphorus per unit of GFR; PO4, Phosphate; $\mathrm{FePO}_{4}$, fractional excretion of Phosphate.

Table 1: Demographic, Dietary Phosphate Intake and Biochemical Characteristics of Study Subjects $(n=80)$. 
Citation: Abbas N, Khan AH, Ghani F, Siddiqui I (2016) Fibroblast Growth Factor 23 (FGF23) Levels, Phosphate Intake and its Association with Indices of Renal Handling of Phosphate in Healthy Volunteers. J Nanomed Nanotechnol 7: 348. doi:10.4172/2157-7439.1000348

Page 3 of 4

\begin{tabular}{|c|c|c|c|}
\hline \multicolumn{3}{|c|}{ Serum Phosphate } & \multirow[t]{2}{*}{$p$-value } \\
\hline & $<2.5(n=6)$ & 2.5 to $4.5(n=73)$ & \\
\hline FGF23 (RU/ml) & $\begin{array}{c}52.3 \\
(\mathrm{IQR}=31.8 \text { to } 75.3)\end{array}$ & $\begin{array}{c}48.6 \\
(I Q R=32.3 \text { to } 81.6)\end{array}$ & 0.988 \\
\hline $\begin{array}{c}\mathrm{TmP/GFR} \\
(\mathrm{mg} / \mathrm{dl})\end{array}$ & $2.1 \pm 0.22$ & $3.1 \pm 0.47$ & $0.000^{\star \star \star}$ \\
\hline $\begin{array}{l}\text { Dietary Phosphate } \\
\text { Intake (mg) }\end{array}$ & $1174 \pm 519$ & $1219 \pm 416$ & 0.563 \\
\hline $\mathrm{FePO}_{4}(\%)$ & $7.9 \pm 4.1$ & $9.1 \pm 4.7$ & 0.468 \\
\hline $\begin{array}{l}\text { Serum Creatinine } \\
(\mathrm{mg} / \mathrm{dl})\end{array}$ & $0.6 \pm 0.2$ & $0.8 \pm 0.2$ & $0.033^{*}$ \\
\hline
\end{tabular}

${ }^{*} \mathrm{p}$-value $<0.05$

${ }^{* * *}$ p-value $<0.001$

Groups were compared by using Mann-Whitney $U$ test. There is significant difference between TmP/GFR and serum creatinine between the two groups. FGF-23, Fibroblast growth factor 23; TmP/GFR, Tubular maximum re-absorption of phosphorus per unit of GFR; $\mathrm{PO}_{4}$, Phosphate; $\mathrm{FePO}_{4}$, fractional excretion of Phosphate.

Table 2: Indices of Renal Handling, Dietary Phosphate Intake and FGF-23 In Subjects With Low and Normal Serum Phosphate Levels $(n=79)$.

\begin{tabular}{|l|c|c|c|}
\hline \multirow{2}{*}{$\begin{array}{l}\text { Independent Variables } \\
\text { (X) }\end{array}$} & \multicolumn{2}{|c|}{ Dependent Variable (Y) } & \multirow{2}{*}{$\boldsymbol{R}^{\mathbf{2}}$} \\
\cline { 2 - 3 } & $\boldsymbol{\beta}$ & $\boldsymbol{P}$ \\
\cline { 2 - 3 } & -0.11 & $\mathbf{0 . 0 3 8}$ & \\
\hline Gender & -0.01 & 0.157 & \\
\hline BMI & 0.00086 & 0.698 & \\
\hline Dietary Phosphate Intake & -2.18 & 0.245 & \multirow{2}{*}{0.598 i.e., } \\
\hline S. Phosphate & -1.44 & $\mathbf{0 . 0 0 9}$ & $59.8 \%$ \\
\hline S. Creatinine & 2.62 & 0.084 & \\
\hline TmP/GFR & 0.12 & $\mathbf{0 . 0 1 9}$ & \\
\hline FePO & & \\
\hline
\end{tabular}

The regression coefficient $\beta$ and $P$ values for potential determinants $(X)$ i.e. Gender. S. Creatinine and $\mathrm{FePO}_{4}$ of FGF23 was positively associated and changes in response to FGF23 levels in healthy individuals. It was calculated by multiple regression analysis in 80 subjects and $R^{2}$ showing good regression of FGF23 i.e. $59.8 \%$. $\mathrm{FePO}_{4}$, fractional excretion of phosphate. Significant $P$ values are shown in bold.

Table 3: Correlates between FGF23 and indices of renal handling

\begin{tabular}{|c|c|c|c|}
\hline & \multicolumn{3}{|c|}{ Median FGF23 } \\
\hline & $\begin{array}{c}\text { Quartile 1 } \\
\mathbf{3 2 . 6}\end{array}$ & $\begin{array}{c}\text { Quartile 2 } \\
\mathbf{4 9 . 3}\end{array}$ & $\begin{array}{c}\text { Quartile 3 } \\
\mathbf{7 3 . 9}\end{array}$ \\
\hline Age & 26 & 30 & 36 \\
\hline S. PO4 & 3.5 & 3 & 2.1 \\
\hline S. CR & 0.8 & 0.5 & 0.9 \\
\hline FEPO4 & 6.87 & 8.79 & 16.58 \\
\hline TmP/GFR & 3.26 & 2.74 & 1.75 \\
\hline TPO & 1588.24 & 1305.87 & 1588.24 \\
\hline
\end{tabular}

Table 4: Distribution of dietary phosphate and indices of renal handling with median FGF23 quartiles.

\begin{tabular}{|c|c|c|c|c|c|}
\hline Study Year & Author & Study Subjects & Population & FGF-23 levels & Other Parameters included \\
\hline 2003 & Jonsson et al. [22] & 141 adult & Caucasians & $55 \pm 50 \mathrm{RU} / \mathrm{ml}$ & Normal Phosphate \\
\hline 2003 & Weber et al. [4] & 42 adults & Caucasians & Median $13 \mathrm{RU} / \mathrm{ml}$ (5 to 210 ) & $\begin{array}{l}\mathrm{Ca}^{2+} 9.5 \pm 0.1 \mathrm{mg} / \mathrm{dl}, \mathrm{PO}_{4} 3.7 \pm 0.1 \mathrm{mg} / \mathrm{dl} \text {, median creatinine } 0.9 \text { (0.6- } \\
1.3) \mathrm{mg} / \mathrm{dl}, \text { median iPTH } 34(11-77) \text {. }\end{array}$ \\
\hline 2005 & Ferrari et al. [24] & 29 healthy males & Swiss & $48.3 \pm 4.6 \mathrm{RU} / \mathrm{ml}$ & $\begin{array}{l}\text { Serum Phosphate } 3.90 \pm 0.09 \mathrm{mg} / \mathrm{dl}, \mathrm{PO}_{4} \text { intake } 1400 \pm 100 \mathrm{mg}, \mathrm{TmP} / \\
\text { GFR } 3.57 \pm 0.09 \mathrm{mg} / \mathrm{dl}, \mathrm{PTH} 26 \pm 2.1 \mathrm{pg} / \mathrm{ml}, 1,25 \mathrm{OH} \text { vit D } 37.5 \pm \\
1.0 \mathrm{pg} / \mathrm{ml} \text {. }\end{array}$ \\
\hline 2009 & Laroche et al.[12] & 15 adults & French & $39.1 \pm 16.4 \mathrm{RU} / \mathrm{ml}$ & $\begin{array}{l}\text { Serum phosphate } 3.2 \pm 0.5 \mathrm{mg} / \mathrm{dl}, \mathrm{PTH} 21 \pm 8 \mathrm{pg} / \mathrm{ml}, \mathrm{Ca}^{2+} 9.7 \pm 0.8 \\
\mathrm{mg} / \mathrm{dl}\end{array}$ \\
\hline 2015 & Abbas et al. & 80 healthy adults & Pakistani & Median 49.9 RU/ml (33-76.1) & $\begin{array}{l}\text { Serum phosphate } 3.35 \pm 3.91 \mathrm{mg} / \mathrm{dl} \text {, dietary Phosphate } 1220 \pm 426 \\
\mathrm{mg}, \mathrm{TmP} / \mathrm{GFR} 3.04 \pm 0.57 \mathrm{mg} / \mathrm{dl}, \mathrm{FePO}_{4} 7.0 \pm 4.7 \%\end{array}$ \\
\hline
\end{tabular}

Table 5: Various studies reporting FGF-23 levels in healthy controls.

\section{Discussion}

FGF23 is a bone-generated major regulator of phosphate homeostasis. It is identified in healthy individuals and its level in our population is comparable with those reported in literature on healthy subjects from other population. Similar findings are seen in the 25 healthy Swiss subjects with high phosphate intake of $1400 \pm 100 \mathrm{mg}$, median FGF23 of $48.3 \pm 4.6 \mathrm{RU} / \mathrm{ml}$ and serum phosphate of $3.90 \pm 0.09$ $\mathrm{mg} / \mathrm{dl}$ (Table 4).

This is the first study from Pakistan that has determined plasma FGF23 levels in healthy subjects. Median plasma FGF23 in apparently normal healthy subjects is 49.9 ( $\mathrm{IQR}=33-76.1$ ), at serum phosphate of $3.3 \pm 3.91 \mathrm{mg} / \mathrm{dl}$ and dietary phosphate intake of $1220.3 \pm 426.4$ mg. Plasma FGF23 was not different between the low and normal phosphate group. Increased $\mathrm{FePO}_{4}$ is seen in the subjects, most likely to be due to high dietary phosphate intake.

Significant association was not found which may be due to small sample size. In addition, parathyroid hormone levels were not measured which has positive effect on urinary phosphate excretion. High PTH is a frequent finding in our population due to prevalent vitamin D deficiency [10].

Serum phosphate homeostasis is a dynamic process and its vivo levels are balanced by a coordinated process including phosphate gut absorption, preservation and efflux of bone and cellular phosphate along with the urinary excretion from the kidneys. It is done mainly by kidneys which maintain serum phosphate levels by controlling its excretion stimulated by changes in dietary pattern of phosphate. Most of the phosphate load is cleared by kidneys and it is considered a vital organ in maintaining the phosphate homeostasis.

Literature showed that disorders of phosphate metabolism are risk factors for cardiovascular complications and these findings lead to phosphate intake restrictions as part of treatment for the enhanced prognosis in patients with cardiovascular diseases as increased phosphate intake was the main causative factor in the studied population. The novel mediators of phosphate metabolism i.e., FGF23 and klotho are linked to dietary phosphate intake and are integral markers of phosphate overload and its bad prognosis.

Furthermore, serum phosphate was weakly associated with FGF23 and it was also not statistically significant in our healthy volunteers whereas a significant correlation was seen with $\mathrm{FePO}_{4}$ and serum creatinine. Westerberg et al. also showed negative linear correlations between FGF23 and phosphate and between FGF23 and TmP/GFR was borderline significant in their small sample done on healthy donors before nephrectomy [11]. Recent literature showed special focus on FGF23 and its association with phosphate homeostasis and vitamin D abnormalities in patients with chronic renal failure. 
Citation: Abbas N, Khan AH, Ghani F, Siddiqui I (2016) Fibroblast Growth Factor 23 (FGF23) Levels, Phosphate Intake and its Association with Indices of Renal Handling of Phosphate in Healthy Volunteers. J Nanomed Nanotechnol 7: 348. doi:10.4172/2157-7439.1000348

Page 4 of 4

Our study has some limitations, first of all, small sample size of the study, which limits the applicability of our findings to other studies. Secondly, we have not assessed the vitamin $\mathrm{D}$, serum calcium levels and PTH in this study which is another well described biologic modifiers of FGF23 i.e., it inhibits $1 a$-hydroxylation of leading to low levels of 1,25 $(\mathrm{OH})_{2} \mathrm{D}$. These findings are significant in our population where there is a high risk of bone diseases due to increased high incidence of vitamin $\mathrm{D}$ deficiency $[12,13]$ and use of a diet which is rich in phosphate and low in calcium. Moreover, Recently FGF23 is also connected to hypertension, obesity and metabolic syndrome which are prevalent in our population. If such data can be authenticated in our population settings, this would represent a key paradigm move that changed FGF23 from biomarker to mechanism of disease, and raises the option of FGF23 being a primary target for intervention.

\section{Acknowledgement}

Study was funded by the Departmental Seed Money Grant for research development (2009), The Aga Khan University (Project ID \# IS SM 090502.). This study was reviewed and approved by Ethical Review Committee (ERC), The Aga Khan University (1314-Path-ERC-09)

\section{References}

1. Shaikh, Berndt T, Kumar R (2008) Regulation of phosphate homeostasis by the phosphatonins and other novel mediators. Pediatr Nephrol 23: 1203-1210.

2. Martin A, David V, Quarles LD (2012) Regulation and function of the FGF23/ klotho endocrine pathways. Physiol Rev 92: 131-155.

3. Dominguez JR, Shlipak MG, Whooley MA, Ix JH (2013) Fractional excretion of phosphorus modifies the association between fibroblast growth factor-23 and outcomes. J Am Soc Nephrol 24: 647-654.
4. Weber TJ, Liu S, Indridason OS, Quarles LD (2003) Serum FGF23 levels in normal and disordered phosphorus homeostasis. J Bone Miner Res 18: 1227-1234.

5. Iqbal R, Haroon MA, Dar FJ, Bilgirami M, Bano G, et al. (2014) Validation of a food frequency questionnaire for assessing macronutrient and calcium intake in adult Pakistani population. J Coll Physicians Surg Pak 24: 224-227.

6. Kassam-Khamis T, Judd PA, Thomas JE (2000) Frequency of consumption and nutrient composition of composite dishes commonly consumed in the UK by South Asian Muslims originating from Bangladesh, Pakistan and East Africa (Ismailis). J Hum Nutr Diet 13: 185-196.

7. Fukumoto S, Yamashita T (2003) Fibroblast growth factor 23 in oncogenic osteomalacia and X-linked hypophosphatemia. N Engl J Med 349: 505-506.

8. Laroche M, Boyer JF, Jahafar H, Allard J, Tack I (2009) Normal FGF23 levels in adult idiopathic phosphate diabetes. Calcif Tissue Int 84: 112-117.

9. Bagga A, Bajpai A, Menon S (2005) Approach to renal tubular disorders. Indian J Pediatr 72: 771-776.

10. Mansoor S, Habib A, Ghani F, Fatmi Z, Badruddin S, et al. (2010) Prevalence and significance of vitamin $D$ deficiency and insufficiency among apparently healthy adults. Clin Biochem 43: 1431-1435.

11. Westerberg PA, Ljunggren O, Larsson TE, Wadström J, Linde T (2010) Fibroblast growth factor-23 and mineral metabolism after unilateral nephrectomy. Nephrol Dial Transplant 25: 4068-4071.

12. Harinarayan CV, Ramalakshmi T, Prasad UV, Sudhakar D, Srinivasarao PV et al. (2007) High prevalence of low dietary calcium, high phytate consumption, and vitamin D deficiency in healthy south Indians. Am J Clin Nutr 85: 1062-1067.

13. Witteveen JE, van Lierop AH, Papapoulos SE, Hamdy NA (2012) Increased circulating levels of FGF23: An adaptive response in primary hyperparathyroidism? Eur J Endocrinol 166: 55-60. 